\title{
Effect of an avidin-biotin binding system on chondrocyte adhesion, growth and gene expression
}

\author{
Wei-Bor Tsai*, Min-Cheng Wang \\ Department of Chemical Engineering, National Taiwan University, No. 1, Roosevelt Rd., Sec. 4, Taipei 106, Taiwan \\ Received 14 March 2004; accepted 17 August 2004 \\ Available online 29 September 2004
}

\begin{abstract}
Cell adhesion to synthetic biomaterials is a prerequisite for anchorage cell culture and tissue engineering. The current study investigated utilization of an avidin-biotin binding system in enhancing chondrocyte adhesion to tissue culture polystyrene (TCPS). Biotinylated chondrocytes adhered to avidin-coated TCPS more quickly than untreated chondrocytes to bare TCPS. Also the avidin-biotin binding system enhanced cell initial spreading. However, the effects were only transient. The growth of biotinylated chondrocytes was first decreased during the first 3 days but increased afterwards. The progeny of biotinylated chondrocytes still maintained the ability in expressing cartilage extracellular matrix proteins such as type II collagen, type IX collagen and aggrecan. These results show potential for the application of the avidin-biotin binding system to cell culture and tissue engineering.
\end{abstract}

(C) 2004 Elsevier Ltd. All rights reserved.

Keywords: Biotin; Avidin; Chondrocytes; Cell adhesion; Cell proliferation; Gene expression

\section{Introduction}

Cell attachment to biomaterials is a crucial step in many biomedical engineering applications such as implants, tissue engineering, biotechnologies and cellbased sensors [1-3]. For example, small-diameter synthetic vascular grafts suffer from occlusion caused by thrombosis [4]. The patency of small synthetic vascular grafts could be improved by retention of an endothelial cell layer in the graft lumen $[5,6]$. In the field of tissue engineering, cell adhesion to degradable scaffolds is a prerequisite for a successful tissue engineering outcome. The retained cells then proliferate and secrete extracellular matrix (ECM) macromolecules to replace gradually degraded scaffolds, and a new tissue is formed. The event of cell adhesion to substrata initiates numerous intracellular processes [7-10], which are critical for a cell's performance in biomedical

\footnotetext{
*Corresponding author. Tel.: + 886-2-2369-8627; fax: + 886-2-23623040.

E-mail address: weibortsai@ntu.edu.tw (W.-B. Tsai).
}

devices. Therefore, cell attachment to synthetic substrates has been an important topic in many biomedical studies.

Cells in native tissues adhere to the surrounding ECM via cell membrane receptors (e.g. integrins [11]) that specifically bind to ECM adhesion proteins such as fibronectin, vitronectin and laminin. Since synthetic biomaterials lack ECM adhesion proteins for specific interactions, cell attachment to artificial biomaterials is merely mediated by non-specific interactions such as ionic attraction, hydrogen bonding and hydrophobic interaction. As a result, cells may adhere rather poorly to synthetic biomaterials, subsequently hampering the effectiveness of a cell-based biomedical device. Therefore, promoting cell adhesion to biomaterials has long been the focus of much research.

Several strategies have been applied to improve affinities between cells and synthetic surfaces. The most favored method is adsorption or conjugation of ECM adhesion proteins to biomaterial surfaces. Precoating artificial substrata with ECM adhesion proteins greatly enhances cell adhesion [12-14]. Alternatively, 
conjugating peptides containing cell-binding sequences (e.g. RGD) has also been shown to improve cell adhesion to biomaterials $[15,16]$. The above approaches are based on the formation of integrinmediated bonds between cell adhesion ligands on substrata and integrin receptors in cell membrane. Therefore, the efficacy of these approaches will depend on the availability of cell-membrane receptors. Cells possessing few functional integrins might not benefit from the above methods.

This problem could be solved by other approaches. For example, precoating of biomaterial surfaces with antibodies against cell-membrane antigens improved cell adhesion onto biomaterials [17,18]. Another approach utilizes a pair of molecules which bind to each other. One molecule is conjugated to cell membrane, and the other one is immobilized to biomaterial surfaces. The bond formation between these two molecules could mediate cell adhesion to biomaterial surfaces. A good example of binding molecule pairs is avidin-biotin. Avidin is a glycoprotein found in egg white, and possesses multiple binding sites for biotin (vitamin $\mathrm{H}$ ). A major distinguishing feature of the avidin-biotin system is its extraordinarily high affinity (the affinity constant, $K_{\mathrm{a}}$, is $10^{13-15} \mathrm{M}^{-1}$ ). Avidin-biotin technology has been extensively applied to biotechnology, such as affinity chromatography, histochemistry, diagnostics, immunoassay and drug delivery [19]. The feasibility of introducing an avidin-biotin binding system for increasing cell attachment has been verified previously. A non-adhesive cell line Ehrilich ascites carcinoma was converted to anchorage-dependent cells by conjugation of biotin molecules on cell membrane [20]. The biotinylated cells not only adhered to avidincoated substrata, but also underwent spreading which involves rearrangement of the cytoskeleton, organization of focal contacts and attainment of cell morphology.

Reichert's group at Duke University has explored the application of the avidin-biotin binding system to a real biomedical problem. Conjugation of biotin molecules to bovine aortic endothelial cells was used to enhance the initial cell attachment to avidin-treated surfaces in order to improve in vivo patency of vascular grafts [21-26]. The high-affinity avidin-biotin binding system increased initial cell adhesion, cell spreading rate and strength of cell attachment [23]. Combination of the avidin-biotin binding system and the intrinsic integrin-dependent adhesion systems further enhanced initial endothelial cell adhesion and spreading [22], focal contact area and resistance to flow [26]. It was suggested that the avidin-biotin system not only helps cell initial adhesion, but also brings cell membrane in close proximity to substrata, which accelerates integrin-mediated linkages between cell membrane integrins and surface-adsorbed serum adhesion proteins [23]. Reichert's studies showed great promise to establish a viable endothelial cell layer on polymeric vascular grafts by the high-affinity avidin-biotin binding system.

The current study explored the possibility of using the avidin-biotin binding system in cell culture and tissue engineering. One general procedure for articular cartilage tissue engineering starts from expansion of limited numbers of autologous chondrocytes, and the cells are then seeded into a degradable scaffold. After being cultured in vitro for a period of time, the newly formed cartilage is then used to repair patients' injured articular cartilage. During this process, not only cell adhesion to cell culture vessels or tissue engineering scaffolds is crucial, but also cell proliferation and phenotype maintenance. Previous studies regarding the avidin-biotin system only concerned short-term cell adhesion and adhesion strength, while little attention was paid to the influence of this system on long-term cell proliferation and phenotype. In this study we intended to evaluate the effects of the avidin-biotin system on chondrocyte adhesion, proliferation and gene expression when cells were cultured on a model material, tissue culture polystyrene (TCPS).

\section{Materials and methods}

\subsection{Chondrocyte isolation}

Articular cartilage samples were dissected aseptically from pig (9-10 month old) knee joints which were obtained from a local abattoir. The articular cartilage samples were diced into approximately $1 \mathrm{~mm}^{3}$ pieces in autoclaved phosphate-buffered saline (PBS, $137 \mathrm{~mm}$ $\mathrm{NaCl}, \quad 2.7 \mathrm{~mm} \quad \mathrm{KCl}, \quad 10 \mathrm{mM} \quad \mathrm{Na}_{2} \mathrm{HPO}_{4}$ and $1.8 \mathrm{~mm}$ $\mathrm{KH}_{2} \mathrm{PO}_{4}$ ) containing $200 \mu \mathrm{g} / \mathrm{ml}$ gentamicin (Gibco, cat. no. 1570064 ) and $25 \mu \mathrm{g} / \mathrm{ml}$ fungizone (Gibco, cat. no. 1520018). After rinsed with PBS three times, $1-2 \mathrm{~g}$ of the cartilage slivers were digested in $10 \mathrm{ml}$ of DMEM/F12 (Gibco, cat. no. 12400-024) containing $1 \mathrm{mg} / \mathrm{ml}$ hyaluronidase (Sigma, cat. no. H-3506) and $1 \mathrm{mg} / \mathrm{ml}$ type I collagenase (Sigma, cat. no. C0130) in a $37{ }^{\circ} \mathrm{C}, 5 \% \mathrm{CO}_{2}$ incubator for $18 \mathrm{~h}$. The digestate was filtered through a $70-\mu \mathrm{m}$ filter cell strainer (Falcon, cat. no. 352350) to remove undigested cartilage lumps. The filtrate was then centrifuged at $200 \times g$ for $10 \mathrm{~min}$, and the cell pellet was resuspended in chondrocyte medium (DMEM/F12 supplemented with $2.5 \mathrm{~mm}$, L-glutamine, $200 \mu \mathrm{g} / \mathrm{ml}$ gentamicin, $25 \mu \mathrm{g} / \mathrm{ml}$ fungizone and $10 \%$ bovine calf serum). Cell number and viability were determined using a hemocytometer with trypan blue exclusion. The freshly isolated (primary) cells were seeded in a T75 flask, grown to confluence in T75 flasks and then retrieved by trypsin treatment for $10 \mathrm{~min}$. The harvested cells were used as passage 1 chondrocytes. 


\subsection{Biotinylation of chondrocytes}

Biotinylation of porcine chondrocytes was performed according to a method using water-soluble N-hydroxysulfosuccinimidobiotin (3-Sulfo-NHS-Biotin, Sigma, cat. no. B5161) [27]. The NHS moiety will react with primary amino groups $\left(-\mathrm{NH}_{2}\right)$ to form stable amide bonds, so biotin molecules could be conjugated to cell membrane proteins via the amide bonds formed between NHS and free amine groups, primarily the epsilon amine group of lysine residue in proteins. Briefly, 3-SulfoNHS-Biotin was added to chondrocyte solution $\left(10^{6}\right.$ cells $/ \mathrm{ml}$ in PBS) to a ratio of $1 \mathrm{mg} / 10^{6}$ cells. The mixture was incubated in ice for $30 \mathrm{~min}$ and then washed with PBS twice by repeating centrifugation and resuspension.

The biotinylated chondrocytes (B-chondrocytes) was visualized by fluorescence microscopy after incubation with avidin-FITC (1 mg/ml, Sigma, A-2901) for $5 \mathrm{~min}$. The extent of biotinylation was determined using the HABA (4'-hydroxyazobenzene-2-carbocylic acid) assay as described previously [22]. This assay is based on that fact that HABA dye binds to avidin and forms a complex which absorbs strongly at $500 \mathrm{~nm}$. When HABA-avidin complex is incubated with biotin, highaffinity biotin will replace $\mathrm{HABA}$ from avidin binding sites, resulting in a decrease in absorbance of HABA-avidin [28]. Briefly, B-chondrocytes were incubated in avidin-HABA reagent $(10 \mathrm{mg}$ of avidin and $600 \mu \mathrm{l}$ of $10 \mathrm{~mm} \mathrm{HABA}$ in $10 \mathrm{~mm} \mathrm{NaOH}$ added to $19.4 \mathrm{ml}$ of PBS) for $5 \mathrm{~min}$. After centrifugation, the absorbance of the supernatant at $490 \mathrm{~nm}$ was measured. A series of known amounts of biotin solution was used to prepare a calibration curve for determining the unknown amount of biotin molecules on cell membrane.

\subsection{Adhesion of biotinylated chondrocytes}

TCPS plates were purchased from Costar (12-well, cat. no. 3513) and used as received. Each TCPS well was incubated with $0.3 \mathrm{ml}$ of avidin solution $(0.1 \mathrm{mg} / \mathrm{ml}$ in PBS) at room temperature for $1 \mathrm{~h}$. After the avidincoated TCPS was rinsed with PBS twice, $4 \times 10^{4} \mathrm{~B}-$ chondrocytes in the serum-free chondrocyte medium were seeded. As the control, untreated chondrocytes in the serum-contained chondrocyte medium were seeded to bare TCPS. At different time points, cell morphology was taken by a phase-contrast microscope and the number of adherent cells was determined by a Hoechst 33258 assay [29]. The adherent chondrocytes were lysed by $10 \mathrm{~mm}$ EDTA in deionized water $(\mathrm{pH} 12.0)$ and then neutralized with $1 \mathrm{~N} \mathrm{KH}_{2} \mathrm{PO}_{4}$ solution ( $\mathrm{pH} 4.0$ ). One hundred microliters of cell lysate were mixed with $1 \mathrm{ml}$ of Hoechst 33258 solution $\left(0.05 \mu \mathrm{g} / \mathrm{ml} \mathrm{H}_{2} \mathrm{O}\right)$ and then the fluorescence at $456 \mathrm{~nm}$ was measured at the excitation wavelength $348 \mathrm{~nm}$. A series of known numbers of chondrocytes (determined by a hemocytometer) was used to generate a calibration curve and the numbers of adherent cells were determined by interpolation. The microscopic images were analyzed by using Image $\mathbf{J}(\mathrm{NIH})$ to determine cell spread area.

In the trypsin treatment experiment, primary chondrocytes were incubated with $0.25 \%$ trypsin-EDTA (GIBCO BRL 25200-072) for 10 or $20 \mathrm{~min}$. Chondrocyte biotinylation was performed after trypsin treatment. Cell adhesion condition was the same as above.

\subsection{Cell growth and gene expression}

The experimental conditions for cell seeding in growth studies were similar to those in cell adhesion experiments except that the cell seeding density was half $\left(2 \times 10^{4}\right.$ cells/well $)$ and only passage 1 chondrocytes were used. After $24 \mathrm{~h}$, unattached cells were rinsed away with PBS thrice, and the wells were filled with fresh chondrocyte medium. Chondrocyte medium was changed every 2 or 3 days. Cell number was determined by the Hoechst 33258 method as described above.

After 7-day culture, expression of $\beta$-actin, type I collagen, type II collagen, type IX collagen and aggrecan genes was analyzed by RT-PCR (reverse transcriptase-polymerase chain reaction) analysis. Total RNA was extracted by using a single-step method modified from an acid guanidinium-thiocyanate-phenolchloroform extract procedure [30]. Briefly, chondrocytes were lysed in $1 \mathrm{ml}$ of $\mathrm{REzol}^{\mathrm{TM}} \mathrm{C} \& \mathrm{~T}$ reagent (PROtech Technology Ent. Co., Taipei, Taiwan) and total RNA was subsequently isolated according to the manufacturer's instructions. Complementary DNA (cDNA) was synthesized from $1 \mu \mathrm{g}$ of total RNA by SUPERSCRIPT $^{\text {TM }}$ II, RNase $\mathrm{H}^{-}$Reverse Transcriptase (cat. no. 18064-014, Invitrogen) using oligo-(dT) priming after incubation at $42^{\circ} \mathrm{C}$ for $50 \mathrm{~min}$. The cDNA was then used as templates for PCR amplification. The primer sequences and the expected length of PCR products for $\beta$-actin, type I collagen, type II collagen, type IX collagen and aggrecan are listed in Table 1. Amplification was performed in a Gene Amp PCR System 9600 thermocycler for 35 cycles of $95^{\circ} \mathrm{C} / 1 \mathrm{~min}$ denaturation, $55^{\circ} \mathrm{C} / 1 \mathrm{~min}$ annealing and $72^{\circ} \mathrm{C} / 1 \mathrm{~min}$ extension, using recombinant Taq DNA polymerase (cat. no. M1861, Promega). The PCR products were analyzed by electrophoresis in a $1 \%$ agarose gel. After staining with ethium bromide, images of resulting bands were taken under UV transillumination using a Kodak Digital Science DC120 camera.

\subsection{Statistics}

Statistical assessment of significant variations was performed by GraphPad Instat ${ }^{\circledR} \quad 3.00$ (GraphPad Software Inc.). Welch-corrected unpaired $t$-test was 
Table 1

Primer sequences for $\beta$-actin, type I collagen, type II collagen, type IX collagen and aggrecan for RT-PCR analysis and predicted length of their PCR products

\begin{tabular}{|c|c|c|}
\hline Encoded protein & Primer sequences & Length (bp) \\
\hline \multirow[t]{2}{*}{$\beta$-actin } & 5'-AACGGCTCCGGCATGTGC-3' & \multirow[t]{2}{*}{543} \\
\hline & 5'-GGATCTTCATGAGGTAGTCAGTC-3' & \\
\hline \multirow[t]{2}{*}{ Type I collagen } & $5^{\prime}-\mathrm{GCTGGCCAACTATGCCTC-} 3^{\prime}$ & \multirow[t]{2}{*}{318} \\
\hline & 5'-GAAACAGACTGGGCCAATG-3' & \\
\hline \multirow[t]{2}{*}{ Type II collagen } & 5'-TGCCTACCTGGACGAAGC--3' & \multirow[t]{2}{*}{449} \\
\hline & 5'-CCCAGTTCAGGCTCTTAG-3' & \\
\hline \multirow[t]{2}{*}{ Type IX collagen } & 5'-TCAGGATTGGCCAAGATGAC-3' & \multirow[t]{2}{*}{352} \\
\hline & 5'-GTCATCTTGGCCAATCCTGA-3' & \\
\hline \multirow[t]{2}{*}{ Aggrecan } & 5'-CTGTTACCGCCACTTCCC-3' & \multirow[t]{2}{*}{441} \\
\hline & $5^{\prime}-$ GGTGCGGTACCAGTGCAC-3' & \\
\hline
\end{tabular}

conducted to determine $p$ values. All data were reported as mean $\pm \mathrm{SD}$.

\section{Results}

\subsection{Biotinylation of chondrocytes}

After incubation with avidin-FITC, all B-chondrocytes showed a green appearance under a fluorescence microscope (Figs. 1A and B) and the control untreated cells did not show any fluorescence (images not shown). The extent of biotinylation was determined to be $3.38 \pm 0.46 \times 10^{9}$ biotin molecules per cell $(n=10)$. The viability of B-chondrocytes was beyond $95 \%$ (determined by trypan blue exclusion).

\subsection{B-chondrocyte adhesion to the avidin-coated TCPS}

Chondrocytes at two different stages were investigated in this study: (i) primary chondrocytes, which were dissociated from cartilage tissues after 18-h collagenase and hyaluronidase digestion, and (ii) passage 1 chondrocytes, which were harvested by trypsin treatment from confluent cell culture.

Adhesion of B-chondrocytes to avidin-coated TCPS in the serum-free medium was first compared to that of normal chondrocytes to bare TCPS in the serumcontained medium. The results indicated that no matter which stages of cells were used, B-chondrocytes adhered better than normal cells in the first hour (Figs. 2A and B, $p<0.01$ ). Adhesion of B-chondrocytes reached a plateau in $4 \mathrm{~h}$ and little increase was observed afterwards (square symbols in Fig. 2A and B). More than $70 \%$ of Bchondrocyte adhesion to the avidin-coated surface happened within the first hour $(83.2 \%$ for the primary cells and $71.5 \%$ for the passage 1 cells). In contrast, adhesion of normal chondrocytes was slow but increased steadily with time at least until $24 \mathrm{~h}$ (diamond symbols in Fig. 2A and B). Only approximately $32 \%$ of
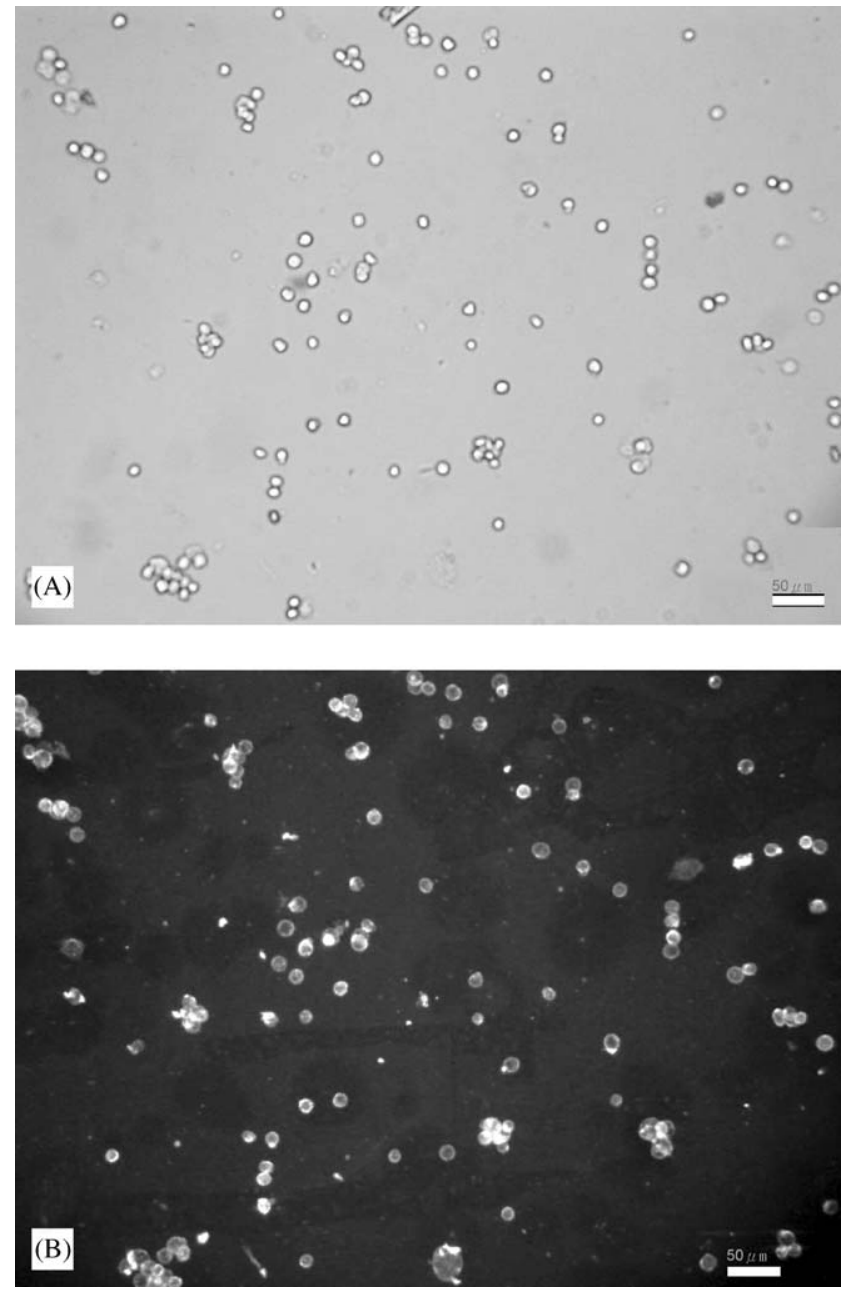

Fig. 1. Phase contrast microphotograph (A) and fluorescent microphotograph (B) of biotinylated passage 1 chondrocytes. The fluorescent image was taken immediately after incubation with avidin-FITC $(1 \mathrm{mg} / \mathrm{ml})$ for $5 \mathrm{~min}$. The bars in the photograph represent $50 \mu \mathrm{m}$.

normal chondrocyte adhesion occurred during the first hour. In spite of low initial adhesion $(1 \mathrm{~h})$, the number of adhered normal primary chondrocytes caught up with 

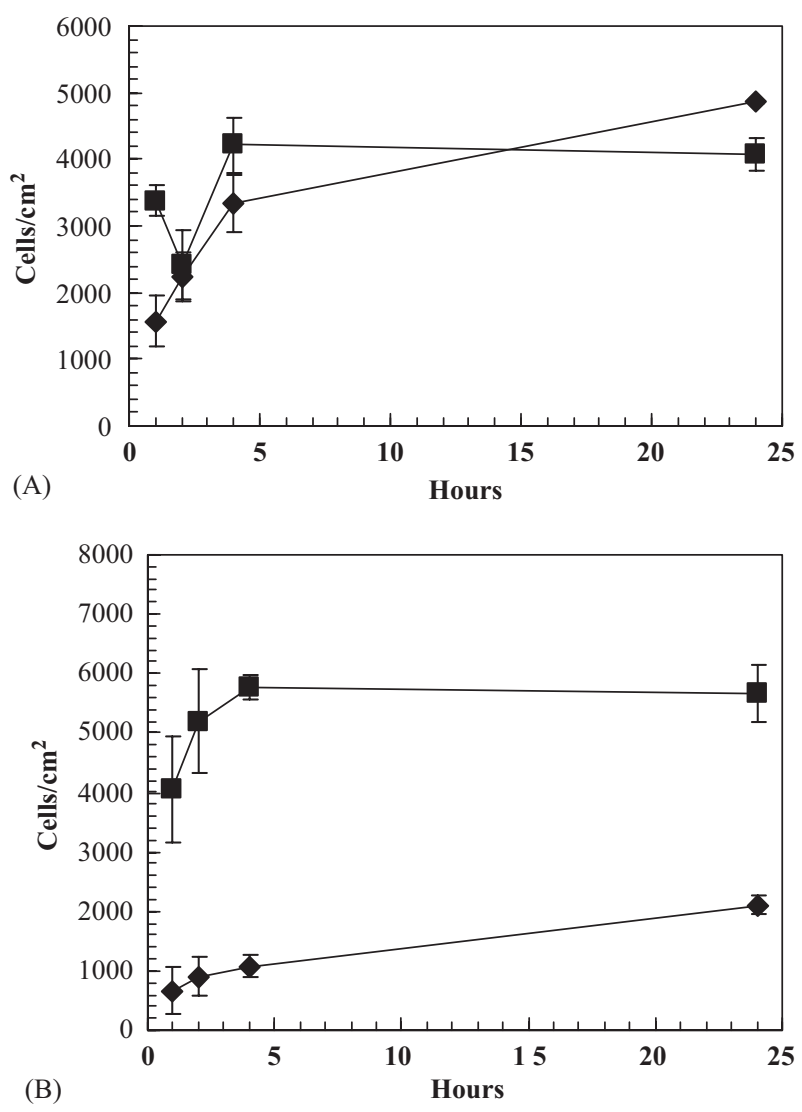

Fig. 2. Adhesion of B-chondrocytes to avidin-adsorbed TCPS in serum-free media (square symbols) and that of normal chondrocytes to untreated TCPS in the serum-contained media (diamond symbols) at the indicated time points. (A) Primary chondrocytes; (B) passage 1 chondrocytes. Cell seeding density was $1 \times 10^{4} \mathrm{cells} / \mathrm{cm}^{2}(n=3)$.

that of B-chondrocytes after $24 \mathrm{~h}$ (Fig. 2A). On the other hand, adhesion of normal passage 1 chondrocytes was still much poorer than that of B-chondrocytes after $24 \mathrm{~h}$ (Fig. 2B, $p<0.001$ ).

Figs. $3 \mathrm{~A}-\mathrm{F}$ show the morphology of adhered passage 1 cells at different time points. After 1-h adhesion many adhered B-chondrocytes already showed a spreading morphology (Fig. 3A), while adherent normal chondrocytes did not spread up to $4 \mathrm{~h}$ (Fig. 3D), although most of the cells did after 1 day (Fig. 3F). Figs. 4A and $\mathrm{B}$ show histograms for the calculated cell spread areas after 4- and 24-h incubation. After 4-h adhesion, more than $50 \%$ of the adherent B-chondrocytes were larger than $1000 \mu \mathrm{m}^{2}$, but most of the adherent normal chondrocytes were less than $500 \mu \mathrm{m}^{2}$. The average areas of the adherent B-chondrocytes were apparently larger than that of the normal chondrocytes $\left(1213.5 \pm 744.0 \mu \mathrm{m}^{2}\right.$ for B-chondrocytes vs. $350.0 \pm 170.7 \mu \mathrm{m}^{2}$ for normal cells, $\left.p<0.01\right)$. After 24-h incubation, the average area of B-chondrocytes decreased significantly $\left(651.8 \pm 282.2 \mu \mathrm{m}^{2}, p<0.001\right.$ vs. 4-h B-chondrocytes). In contrast, the average area of normal chondrocyte increased greatly during the same period $\left(936.6 \pm 444.7 \mu \mathrm{m}^{2}, \quad p<0.001\right.$ vs. 4-h normal chondrocytes) and larger than that of B-chondrocytes $(p<0.001)$.

Adhesion of B-chondrocytes to bare TCPS in $1 \mathrm{~h}$ was comparable to that of normal chondrocytes (comparing the rightmost two bars in Figs. 5A and B). The adhesion of B-chondrocytes to the avidin-bound surfaces was higher than the adhesion of normal chondrocytes to the bare TCPS no matter whether the culture media contained serum or not (Figs. 5A and B). It is interesting to note that adhesion of primary B-chondrocytes was slightly higher in the serum-contained medium than that in the serum-free medium, while the opposite trend was found on passage $1 \mathrm{~B}$-chondrocytes (comparing the leftmost two bars in Figs. 5A and B). Nevertheless, the difference in both cases was not significant $(p>0.05)$.

Since adhesion of passage 1 chondrocytes was found to be lower than that of primary chondrocytes (comparing diamond symbols in Figs. 5A and B), we speculated that trypsin treatment might damage the adhesive ability of chondrocytes. Fig. 6A shows that trypsin-treatment significantly decreased adhesion of primary chondrocytes $(p<0.05)$. The trypsin treatment also decreased adhesion of B-chondrocytes to the avidin-bound surfaces no matter whether chondrocyte media contained serum or not (Fig. 6B).

\subsection{B-chondrocyte growth and gene expression}

The influence of biotinylation on growth of passage 1 chondrocytes and gene expression was next evaluated in the current study. The number of adherent passage $1 \mathrm{~B}-$ chondrocytes was initially higher than that of normal chondrocytes on Day 1 (Fig. 7). However, the number of B-chondrocytes on the avidin-coated surfaces was decreased during the first 3 days, but the B-cells resumed growing afterwards (doubling time $18.7 \mathrm{~h}$ from Day 3 and Day 7). In contrast, the number of normal cells had been steadily increased with time since the first day (doubling time $23.5 \mathrm{~h}$ from Day 1 and Day 3, and $34.0 \mathrm{~h}$ from Day 3 to Day 7). On Day 7, the number of normal chondrocytes was higher than that of B-chondrocytes. Furthermore, we found that many adherent B-chondrocytes already lost the surface biotin moiety on Day 1 (Figs. 8A and B), and after Day 3 almost none of adherent B-chondrocytes showed any fluorescence (images not shown).

RT-PCR analysis indicated that the progeny of Bchondrocytes still expressed the characteristic markers for functional chondrocytes, such as type II collagen, type IX collagen and aggrecan (Fig. 9). Both Bchondrocytes and normal chondrocytes showed a sign of de-differentiation, i.e. expression of type I collagen. The expression of type IX collagen gene was higher in Bchondrocytes than in normal chondrocytes. 

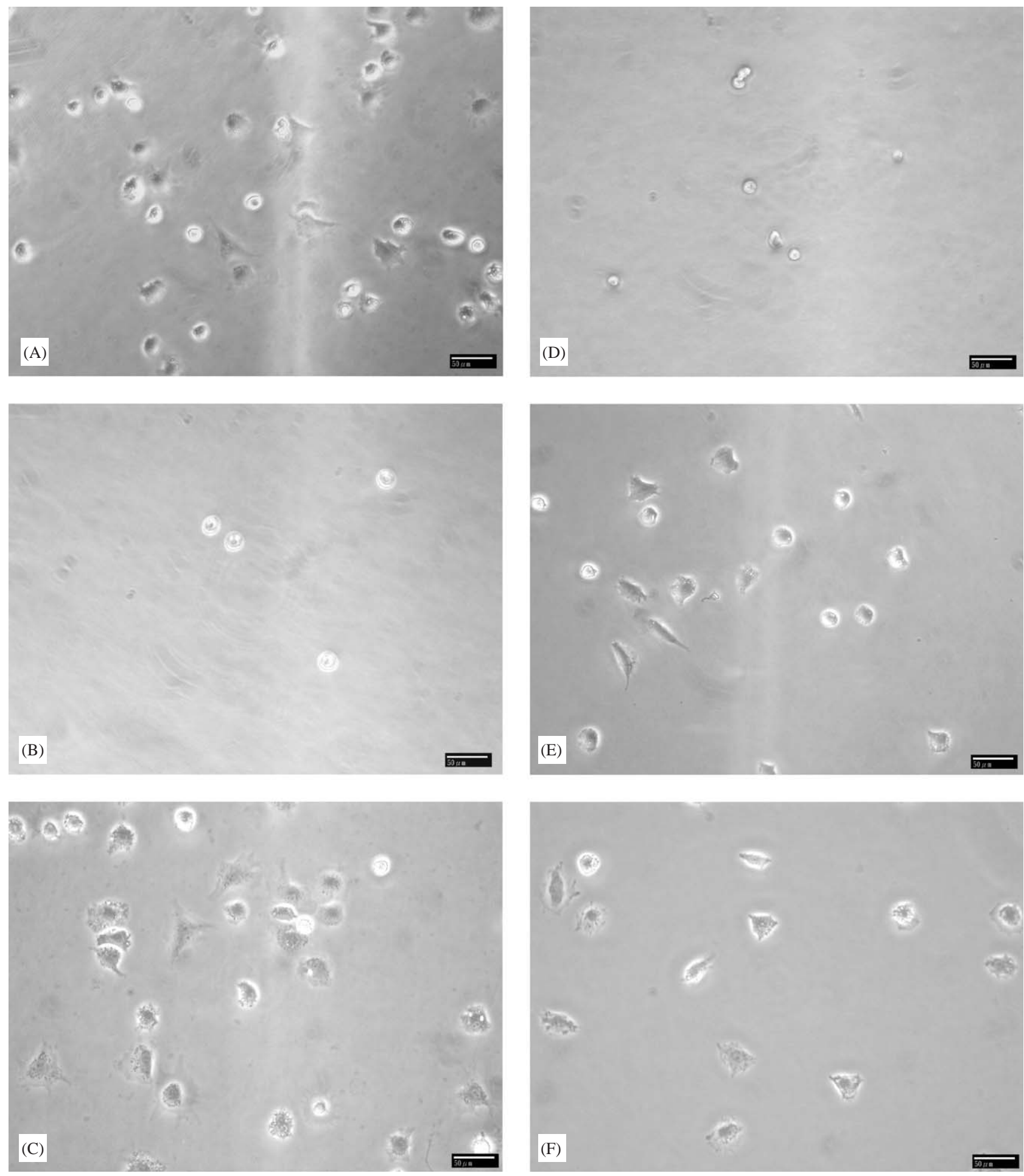

Fig. 3. Phase contrast microphotographs of adherent passage 1 B-chondrocytes (A, C, E) and normal chondrocytes (B, D, F) at different time points. (A and B) $1 \mathrm{~h}$; (C and D) $4 \mathrm{~h}$; (E and F) $24 \mathrm{~h}$. First-passage chondrocytes were used. The bars in the photograph represent $50 \mu \mathrm{m}$.

\section{Discussion}

The methods for cell biotinylation and for avidin immobilization used in the current study were slightly different from those in Reichert's studies [22]. First, in
Reichert's studies, adherent cells were biotinylated in cell culture flasks and the biotinylated cells were later detached from the substrata by trypsin digestion. Their approach may limit the extent of biotin conjugation on cell membranes, since (i) when cells are adherent on 

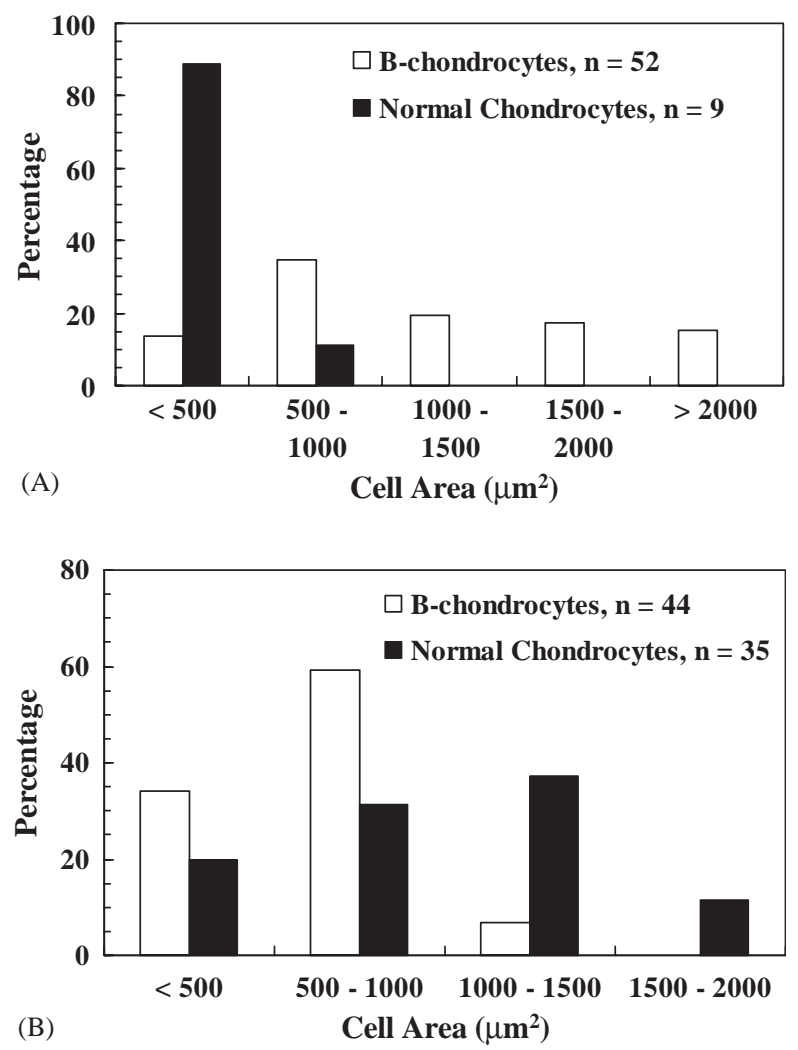

Fig. 4. Histogram analysis for cell spread area of adherent Bchondrocytes and normal chondrocytes at different time points. (A) $4 \mathrm{~h}$; (B) $24 \mathrm{~h}$.

substrata, membrane proteins on the basal side might not be accessible for biotinylation, and (ii) trypsin treatment following biotinylation might remove biotinylated membrane proteins. In contrast, suspended cells underwent biotinylation in the current study. We tested these two methods and found that the numbers of membrane-bound biotin molecules were much higher using our method than Reichert's method $\left(3.4 \times 10^{9}\right.$ biotin molecules/cell vs. $2.5 \times 10^{8}$ biotin molecules/cell).

Secondly, avidin was adsorbed to TCPS directly in this study, whereas Reichert's group used an indirect adsorption method-i.e. pre-adsorption of biotinylated bovine serum albumin (b-BSA) to substrates prior to avidin adsorption. We compared these two approaches by the following method. Fluorescently labeled avidinFITC $(0.1 \mathrm{mg} / \mathrm{ml})$ was adsorbed to bare TCPS or b-BSA pre-adsorbed TCPS $(1 \mathrm{mg} / \mathrm{ml} \mathrm{BSA})$. The concentration of unbound avidin-FITC was determined by a fluorophotometer. The total amount of bound avidin-FITC was calculated by subtracting the amount of unbound avidin-FITC from that of the total avidin-FITC added. More avidin-FITC molecules were immobilized using the direct adsorption method than using the indirect adsorption one $\left(0.545 \mu \mathrm{g} / \mathrm{cm}^{2}\right.$ vs. $\left.0.289 \mu \mathrm{g} / \mathrm{cm}^{2}\right)$. However, it should be noted that the affinity of FITC-labeled avidin is not the same as that of unlabeled avidin. We
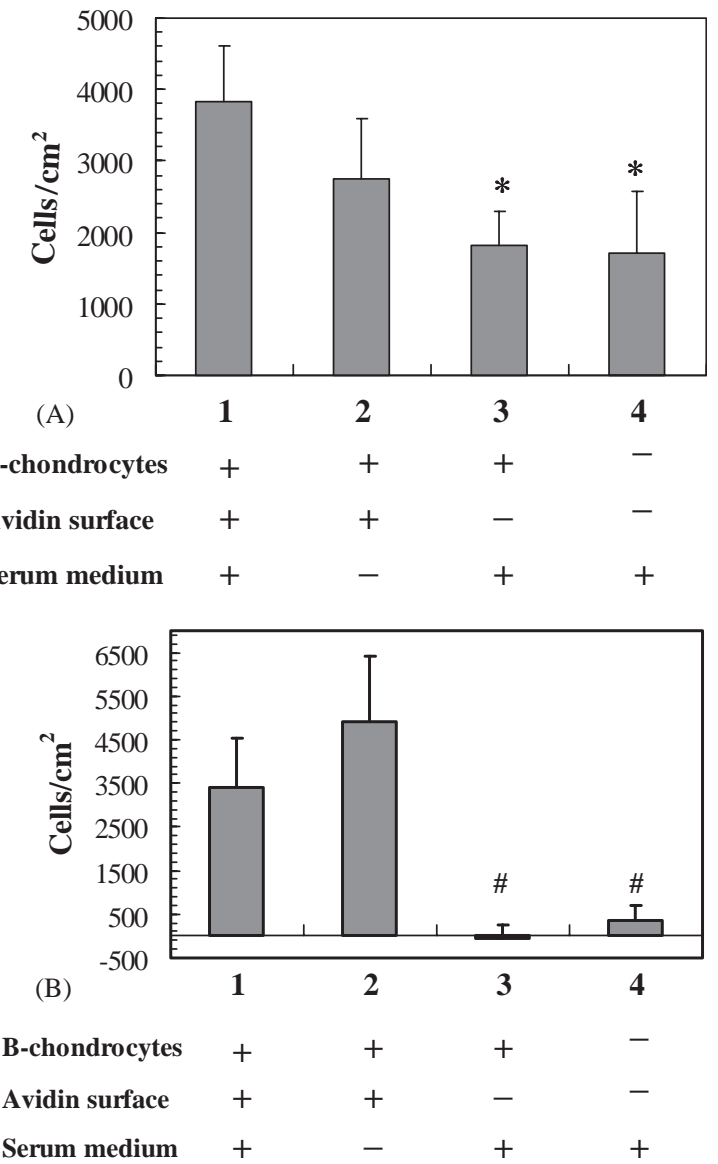

Fig. 5. One-hour cell adhesion for (A) primary chondrocytes and (B) passage 1 chondrocytes at various conditions. B-chondrocytes were used at conditions 1-3 while normal chondrocytes were used at condition 4. No serum was added to serum at condition 2. TCPS surfaces were not coated with avidin at conditions 3 and 4 . Cell seeding density was $1 \times 10^{4}$ cells $/ \mathrm{cm}^{2}(n=3) .{ }^{*} p<0.05$ vs. condition $1 ; \# p<0.01$ vs. condition 1 or 2 .

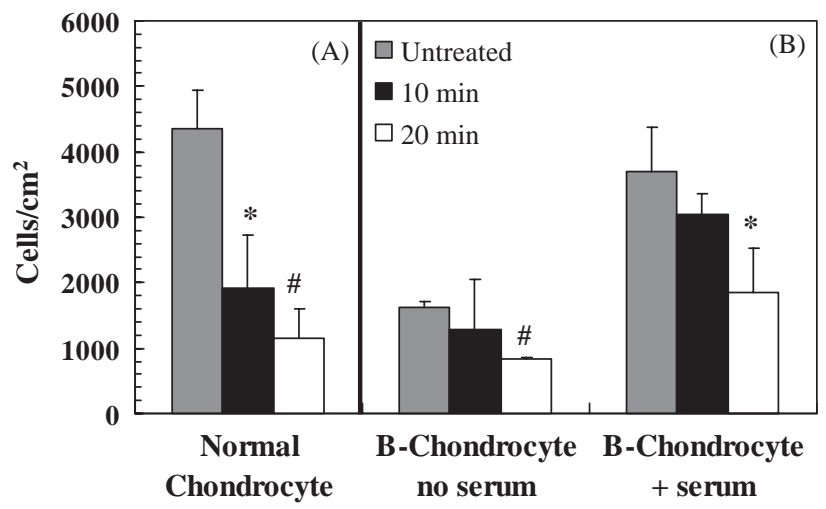

Fig. 6. One-hour adhesion of trypsin-treated primary chondrocytes for 10 or $20 \mathrm{~min}$. (A) Normal chondrocytes; (B) B-chondrocytes in serum-contained or serum-free media. Biotinylation underwent after trypsin treatment. Cell seeding density was $1 \times 10^{4}$ cells $/ \mathrm{cm}^{2}(n=3)$. ${ }^{*} p<0.05$ vs. the corresponding untreated cells; $\# p<0.001$ vs. the corresponding untreated cells. 


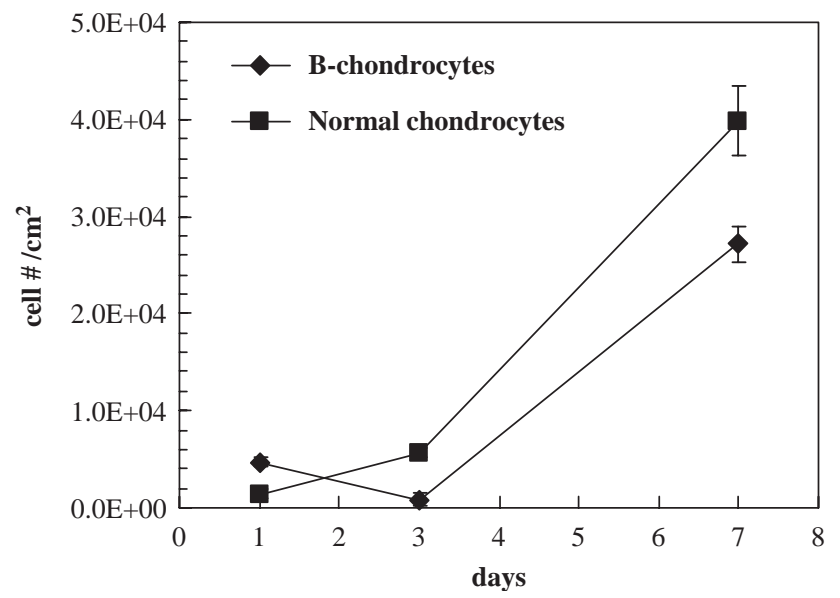

Fig. 7. Growth curve for the passage 1 chondrocytes. B-chondrocytes $(-)$ were seeded to avidin-coated TCPS in serum-free media, while normal chondrocytes (- - ) were seeded to bare TCPS in serumcontained media. The next day all media were replaced with fresh serum-contained media. Chondrocyte media were then changed every 2 or 3 days. Cell seeding density was $5 \times 10^{3}$ cells $/ \mathrm{cm}^{2}(n=3)$.

found that the affinity of unlabeled avidin to TCPS was at least twice that of labeled avidin by comparing adsorption of labeled and unlabeled avidin mixture with a series of ratios. Therefore, the above adsorption values may only represent the relative adsorption by the two methods, but not the absolute values.

We suggest that increasing cell membrane biotin concentration and avidin surface density could benefit cell adhesion mediated by avidin-biotin binding. Therefore, the methods described here were used for cell biotinylation and avidin immobilization.

The avidin-biotin binding systems greatly enhanced the initial cell adhesion $(1 \mathrm{~h})$ to the avidin-coated surfaces (Figs. 2A and B). The high-affinity binding between avidin and biotin provides a mechanism for quick adhesion of B-chondrocytes. It was reported that adhesion strength of biotinylated endothelial cells was significantly higher than that of non-modified cells [23]. Cell adhesion strength has been suggested to be related to the log of the affinity constant [31]. Therefore, the binding affinity between avidin and biotin $\left(K_{\mathrm{a}}=10^{13-15} \mathrm{M}^{-1}\right)$ would increase cell adhesion strength by a factor of 2-3 over typical bond affinities of integrin receptors with serum adhesive protein $\left(K_{\mathrm{a}}=10^{8} \mathrm{M}^{-1}\right)$ for the same amount of bonds. The avidin-binding system also initiated fast cell spreading (comparing Fig $3 \mathrm{~A}$ to Fig $3 \mathrm{~B}$, and Fig $3 \mathrm{C}$ to Fig $3 \mathrm{D}$; Fig. 4A).

However, the impetus of the avidin-biotin binding system in mediating cell adhesion did not last long. More than $70 \%$ of B-chondrocytes adhered in the first hour and no obvious B-chondrocyte adhesion was observed after $4 \mathrm{~h}$ (square symbols in Figs. $2 \mathrm{~A}$ and B).
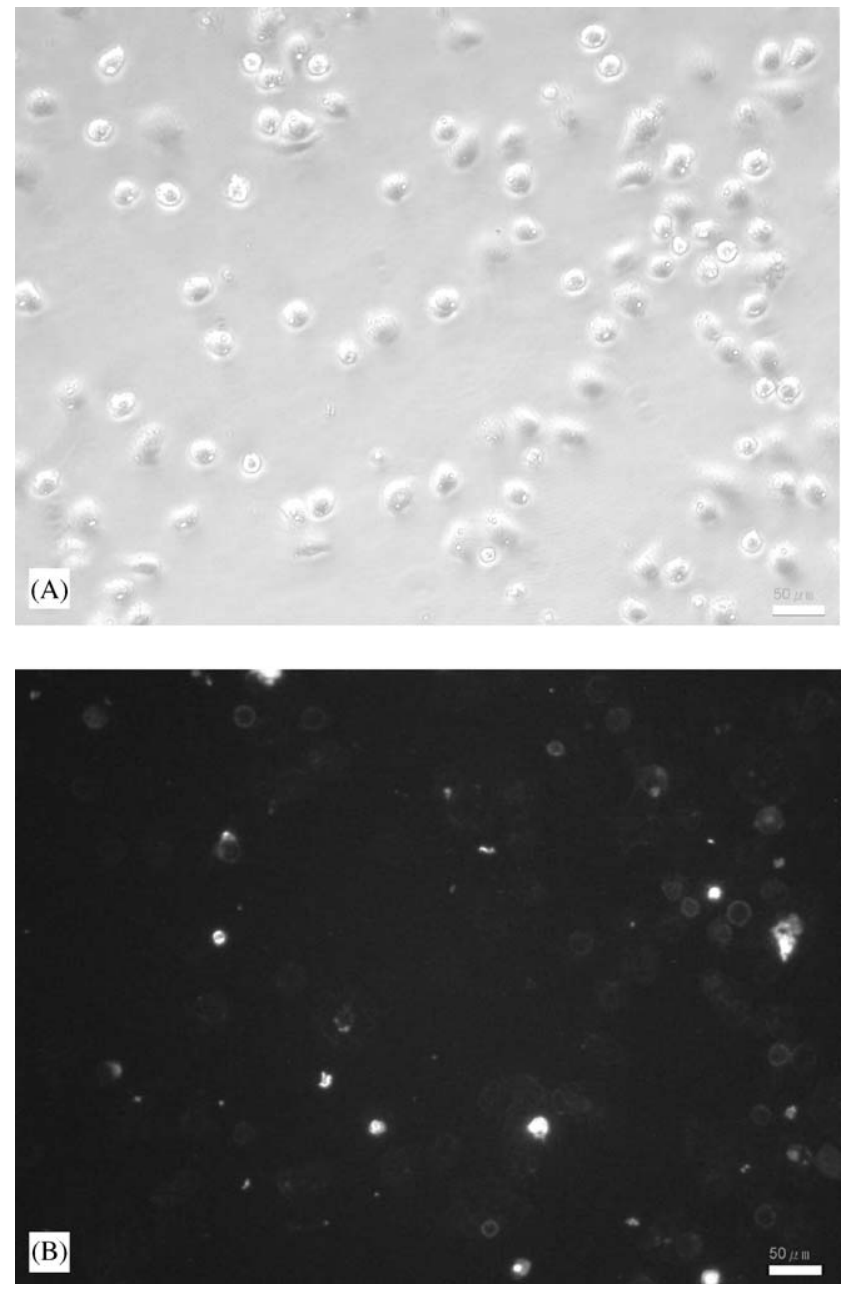

Fig. 8. Phase contrast microphotograph (A) and fluorescent microphotograph (B) of adherent biotinylated passage 1 chondrocytes on Day 1. The fluorescent image was taken after incubation with avidinFITC $(1 \mathrm{mg} / \mathrm{ml})$ for $5 \mathrm{~min}$. The bars in the photograph represent $50 \mu \mathrm{m}$.

The reason may be due to internalization of membrane biotin molecules, which is discussed in detail later. On the other hand, the integrin-dependent binding system provided a slow but long-term mechanism for normal chondrocyte adhesion. Less than $32 \%$ of adhesion occurred during the first hour and cells continued to adhesion at least until $24 \mathrm{~h}$ (Figs. 2A and B). Although adhesion of normal chondrocyte to TCPS was initially lower than B-chondrocyte adhesion, after $24 \mathrm{~h}$ adhesion of primary normal chondrocytes was higher than that of B-chondrocytes (Fig. 2A). However, 24-h adhesion of passage 1 normal chondrocytes was still much lower than that of B-chondrocytes (Fig. 2B). Together with the observation that primary chondrocytes adhered much better than passage 1 cells (comparing the diamond symbols in Figs. 2A and B), it suggested that adhesivity of passage 1 chondrocytes seemed poorer than primary cells. 


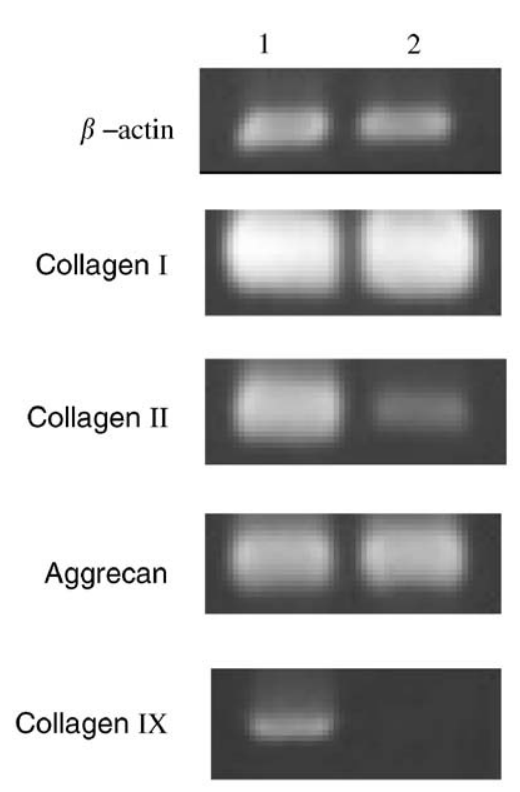

Fig. 9. RT-PCR analysis of the genes encoding $\beta$-actin, type I collagen, type II collagen, type IX collagen and aggrecan in chondrocytes cultured for 7 days. Line 1: B-chondrocytes; line 2: normal chondrocytes.

The discrepancy in cell adhesivity might be due to the isolation method. Passage 1 cells were retrieved from cell culture flasks by using trypsin, which might damage membrane-associated integrins. It was reported that the prolonged exposure of cells to active trypsin might damage cell viability [32]. On the other hand, primary chondrocytes was harvested by using collagenase and hyaluronidase, which only digest ECM collagens and hyaluronic acid but not cell membrane proteins. Therefore, low adhesivity in passage 1 chondrocytes might be due to trypsin treatment. The above speculation was confirmed by the result that trypsin-treated primary chondrocytes was decreased in cell adhesivity (Fig. 6A). Our study indicated that the avidin-biotin system is especially useful in enhancing adhesion of cells with poor adhesivity.

By comparing the rightmost two bars in Fig. 5A or B, B-chondrocytes adhered to bare TCPS in the serumcontained medium similar to normal chondrocytes, suggesting that conjugation of small biotin molecules to cell-membrane proteins did not influence their intrinsic ability in mediating cell adhesion. Therefore, B-chondrocyte adhesion to the avidin-coated TCPS might be further increased by the presence of serum. Combination of the avidin-biotin system and the integrin-mediated system (via serum adhesion proteins) slightly enhanced adhesion of primary B-chondrocytes (comparing the leftmost two bars in Fig. 5A), but tended to decrease adhesion of passage 1 chondrocytes (comparing the leftmost two bars in Fig. 5B). One of the explanations is that low adhesivity of first-passage normal chondrocytes did not support integrin-mediated adhesion very well. Besides, sugar moieties on avidin molecules may lead to non-specific or other undesired interactions with serum proteins [33]. Non-specific binding of serum proteins (especially passive proteins) to surface-bound avidin might influence binding between avidin and cell-membrane biotin.

Enhancement of cell adhesion to synthetic materials is only an initial step for applying the avidin-biotin system to cell culture and tissue engineering. The next step is to ensure that adherent B-cells can proliferate and perform their normal functions. This attempt was first discouraged by the fact that the number of B-chondrocytes was decreased during the first 3 days although increased afterwards (diamond symbols in Fig. 7). Our first supposition was that the biotinylation process might induce cell apoptosis although the viability of Bchondrocytes immediately after biotinylation still retained more than $95 \%$. This assumption was tested by incubation of Day 2 B-chondrocytes with BCECF-AM (2',7'-bis-(2-carboxyethyl)-5(6)-carboxyfluorescein acetoxymethylester, for staining live cells) and propidium iodide (for staining apoptotic cells). No sign of apoptosis in B-chondrocytes was found. Therefore, decrease in cell number was not likely due to cell apoptosis.

Another possibility might be due to internalization of membrane-conjugated biotin molecules. It has been reported that fluorescein-labeled avidin bound throughout biotinylated cells, but shifted to the cell interior in $24 \mathrm{~h}$ [27]. Our result also shows that the biotin moiety on B-chondrocyte membrane was greatly decreased after 1 day incubation (Fig. 8) and not detectable on Day 3. Endocytosis of biotin molecules deprives the availability of biotin molecules on cell membrane and limits bond formation with surface-bound avidin. This is one explanation for the transient ability of the avidin-biotin binding system in mediating cell adhesion. The decrease in B-chondrocyte spread area with time (Fig. 4) suggests that even the biotin molecules which already bind to surface avidin might be internalized as well. Therefore, B-chondrocytes might detach from avidin-coated surfaces. Furthermore, progeny of B-chondrocytes should not have any biotin molecules on the membrane, so they might not be able to stick on avidin-coated surfaces. Nevertheless, B-chondrocytes proliferated on the avidincoated surfaces very well after Day 3 (Fig. 7). The possible reason may be that the surface-bound avidin was replaced by serum proteins or cell-secreted adhesion proteins. Therefore, the avidin-adsorbed surfaces were modulated and suitable for cell growth after Day 3. Biotin internalization undermines utilization of the avidin-biotin system in long-term cell attachment and cell culture. Strategies to solve this problem may include inhibition of biotin internalization, and co-adsorption of avidin and adhesion proteins to surfaces.

Another crucial issue regarding application of the avidin-biotin system in chondrocyte culture or cartilage 
tissue engineering is whether cell-membrane biotinylation or biotin internalization alters chondrocyte phenotype. Chondrocyte de-differentiation is a well-known problem in chondrocyte expansion in vitro, especially in monolayer culture. Cultured chondrocytes quickly transform their characteristically round shape into a fibroblast-like morphology [34], stop secreting type II collagen and aggrecan, and secrete type I collagen [35-37]. De-differentiated chondrocytes cannot form hyaline cartilage but mechanically inferior fibrocartilage. Several studies showed that chondrocytes with round shape is associated with synthesis of type II collagen and cartilage-specific proteoglycans $[34,38,39]$. In contrast, flattened fibroblast-like chondrocytes were shown with decreased synthesis of type II collagen and aggrecan, and with increased synthesis of type I collagen $[38,40]$. The initial quick spread of B-chondrocytes caused a concern about early cell de-differentiation. RT-PCR analysis indicated that the gene expression pattern in B-chondrocytes was similar to that in normal chondrocytes (Fig. 9). The expression levels of type II collagen and type IX collagen in cultured B-chondrocytes were higher than those in the untreated cells. Since RT-PCR is not a quantitative method for gene expression, it cannot be concluded that cultured Bchondrocytes are more like functional chondrocytes than untreated cells are. However, at least we can conclude that biotinylation was not a reason for chondrocyte de-differentiation.

\section{Conclusion}

The high-affinity avidin-biotin binding system increased initial attachment of chondrocytes to TCPS, especially for passage 1 chondrocytes with low adhesivity. Biotinylated cells were still able to proliferate. Compared to gene expression in normal chondrocytes, biotinylation did not induce chondrocytes toward dedifferentiation. However, internalization of membranebound biotin may result in detachment of B-chondrocyte from avidin-coated surfaces. Problems caused by biotin internalization need to be resolved before the avidin-biotin system can be applied to cell culture and tissue engineering. In conclusion, the current study provides an insight into applicability of the avidin-biotin system in cell culture and tissue engineering. We believe that this system can be a powerful tool when applied to cells with low adhesivity.

\section{Acknowledgment}

The authors thank National Science Council, ROC (NSC-91-2218-E-002-032) for financial support.

\section{References}

[1] Castner DG, Ratner BD. Biomedical surface science: foundations to frontiers. Surf Sci 2002;500:28-60.

[2] Hubbell JA. Biomaterials in tissue engineering. Bio-Technology 1995;13:565-76.

[3] Kasemo B. Biological surface science. Surf Sci 2002;500:656-77.

[4] Didisheim P, Watson JT. Cardiovascular applications. In: Ratner BD, Hoffman AS, Schoen FJ, Lemons JE editors. Biomaterials science: an introduction to materials in medicine. San Diego, USA: Academic Press; 1996. p. 283-97.

[5] Walluscheck KP, Steinhoff G, Kelm S, Haverich A. Improved endothelial cell attachment on ePTFE vascular grafts pretreated with synthetic RGD-containing peptides. Eur J Vasc Endovasc Surg 1996;12:321-30.

[6] Pollara P, Alessandri G, Bonardelli S, Simonini A, Cabibbo E, Portolani N, et al. Complete in vitro prosthesis endothelialization induced by artificial extracellular matrix. J Invest Surg 1999; 12:81-8.

[7] Benecke BJ, Ben-Ze'ev A, Penman S. The control of mRNA production, translation and turnover in suspended and reattached anchorage-dependent fibroblasts. Cell 1978;14:931-9.

[8] Schwartz MA, Lechene C. Adhesion is required for protein kinase C-dependent activation of the $\mathrm{Na}^{+} / \mathrm{H}^{+}$antiporter by plateletderived growth factor. Proc Natl Acad Sci USA 1992;89:6138-41.

[9] Folkman J, Moscona A. Role of cell shape in growth control. Nature 1978;273:345-9.

[10] Ben-Ze'ev A, Farmer SR, Penman S. Protein synthesis requires cell-surface contact while nuclear events respond to cell shape in anchorage-dependent fibroblasts. Cell 1980;21:365-72.

[11] Hynes RO. Integrins: versatility, modulation, and signaling in cell adhesion. Cell 1992;69:11-25.

[12] Balcells M, Edelman ER. Effect of pre-adsorbed proteins on attachment, proliferation, and function of endothelial cells. J Cell Physiol 2002;191:155-61.

[13] Kikuchi A, Taira H, Tsuruta T, Hayashi M, Kataoka K. Adsorbed serum protein mediated adhesion and growth behavior of bovine aortic endothelial cells on polyamine graft copolymer surfaces. J Biomater Sci Polym Ed 1996;8:77-90.

[14] van Wachem PB, Vreriks CM, Beugeling T, Feijen J, Bantjes A, Detmers JP, et al. The influence of protein adsorption on interactions of cultured human endothelial cells with polymers. J Biomed Mater Res 1987;21:701-18.

[15] Massia SP, Hubbell JA. Covalently attached GRGD on polymer surfaces promotes biospecific adhesion of mammalian cells. Ann N Y Acad Sci 1990;589:261-70.

[16] Massia SP, Hubbell JA. Human endothelial cell interactions with surface-coupled adhesion peptides on a nonadhesive glass substrate and two polymeric biomaterials. J Biomed Mater Res 1991;25:223-42.

[17] Grinnell F, Ho CH, Tuan TL. Cell adhesion and phagocytosis promoted by monoclonal antibodies not directed against fibronectin receptors. J Cell Sci 1988;90(Pt 2):201-14.

[18] Dekker A, Poot AA, van Mourik JA, Workel MP, Beugeling T, Bantjes A, et al. Improved adhesion and proliferation of human endothelial cells on polyethylene precoated with monoclonal antibodies directed against cell membrane antigens and extracellular matrix proteins. Thromb Haemost 1991;66: 715-24.

[19] Wilchek M, Bayer EA. Introduction to avidin-biotin technology. In: Wilchek M, Bayer EA editors. Methods in enzymology. San Diego: Academic Press Inc.; 1990. p. 5-13.

[20] Bogdanov Jr AA, Gordeeva LV, Baibakov BA, Margolis LB, Torchilin VP. Restoration of adhesive potentials of Ehrlich ascites carcinoma cells by modification of plasma membrane. J Cell Physiol 1991;147:182-90. 
[21] Bhat VD, Klitzman B, Koger K, Truskey GA, Reichert WM. Improving endothelial cell adhesion to vascular graft surfaces: clinical need and strategies. J Biomater Sci Polym Ed 1998;9:1117-35.

[22] Bhat VD, Truskey GA, Reichert WM. Fibronectin and avidinbiotin as a heterogeneous ligand system for enhanced endothelial cell adhesion. J Biomed Mater Res 1998;41:377-85.

[23] Bhat VD, Truskey GA, Reichert WM. Using avidin-mediated binding to enhance initial endothelial cell attachment and spreading. J Biomed Mater Res 1998;40:57-65.

[24] Chan BP, Bhat VD, Yegnasubramanian S, Reichert WM, Truskey GA. An equilibrium model of endothelial cell adhesion via integrin-dependent and integrin-independent ligands. Biomaterials 1999;20:2395-403.

[25] Mathur AB, Chan BP, Truskey GA, Reichert WM. High-affinity augmentation of endothelial cell attachment: long-term effects on focal contact and actin filament formation. J Biomed Mater Res 2003;66A:729-37.

[26] Mathur AB, Truskey GA, Reichert WM. Synergistic effect of high-affinity binding and flow preconditioning on endothelial cell adhesion. J Biomed Mater Res 2003;64A:155-63.

[27] Wojda U, Goldsmith P, Miller JL. Surface membrane biotinylation efficiently mediates the endocytosis of avidin bioconjugates into nucleated cells. Bioconjug Chem 1999;10:1044-50.

[28] Green NM. A spectrophotometric assay for avidin and biotin based on binding of dyes by avidin. Biochem J 1965;94:23c-4c.

[29] Kim YJ, Sah RL, Doong JY, Grodzinsky AJ. Fluorometric assay of DNA in cartilage explants using Hoechst 33258. Anal Biochem 1988;174:168-76.

[30] Chomczynski P, Sacchi N. Single-step method of RNA isolation by acid guanidinium thiocyanate-phenol-chloroform extraction. Anal Biochem 1987;162:156-9.
[31] Kuo SC, Lauffenburger DA. Relationship between receptor/ ligand binding affinity and adhesion strength. Biophys $\mathbf{J}$ 1993;65:2191-200.

[32] Freshney RI. Culture of animal cells, 4th ed. New York: WileyLiss; 2000.

[33] Bayer EA, Wilchek M. The use of the avidin-biotin complex as a tool in molecular biology. Methods Biochem Anal 1980;26:1-45.

[34] von der Mark K, Gauss V, von der Mark H, Muller P. Relationship between cell shape and type of collagen synthesised as chondrocytes lose their cartilage phenotype in culture. Nature 1977;267:531-2.

[35] Archer CW, McDowell J, Bayliss MT, Stephens MD, Bentley G. Phenotypic modulation in sub-populations of human articular chondrocytes in vitro. J Cell Sci 1990; 97(Pt 2):361-71.

[36] Lefebvre V, Peeters-Joris C, Vaes G. Production of collagens, collagenase and collagenase inhibitor during the dedifferentiation of articular chondrocytes by serial subcultures. Biochim Biophys Acta 1990;1051:266-75.

[37] Aulthouse AL, Beck M, Griffey E, Sanford J, Arden K, Machado MA, et al. Expression of the human chondrocyte phenotype in vitro. In Vitro Cell Dev Biol 1989;25:659-68.

[38] Benya P, Schaffer J. Dedifferentiated chondrocytes reexpress the differentiated collagen phenotype when cultured in agarose gels. Cell 1982;30:215-24.

[39] Glowacki J, Trepman E, Folkman J. Cell shape and phenotypic expression in chondrocytes. Proc Soc Exp Biol Med 1983; 172:93-8.

[40] Watt FM, Dudhia J. Prolonged expression of differentiated phenotype by chondrocytes cultured at low density on a composite substrate of collagen and agarose that restricts cell spreading. Differentiation 1988;38:140-7. 